\title{
Assembly force and taper angle difference influence the relative motion at the stem-neck interface of bi-modular hip prostheses
}

Proc IMechE Part H:

$J$ Engineering in Medicine

2016, Vol. 230(7) 690-699

(C) IMechE 2016

Reprints and permissions:

sagepub.co.uk/journalsPermissions.nav DOI: $10.1177 / 0954411916648717$

pih.sagepub.com

(SAGE

\author{
Henning Haschke', Sabrina Y Jauch-Matt ${ }^{1,2}$, Kay Sellenschloh', \\ Gerd Huber' and Michael M Morlock'
}

\begin{abstract}
Bi-modular hip arthroplasty prostheses allow adaptation to the individual patient anatomy and the combination of different materials but introduce an additional interface, which was related lately to current clinical issues. Relative motion at the additional taper interface might increase the overall risk of fretting, corrosion, metallic debris and early failure. The aim of this study was to investigate whether the assembly force influences the relative motion and seating behaviour at the stem-neck interface of a bi-modular hip prosthesis (Metha ${ }^{\circledR}$; Aesculap AG, Tuttlingen, Germany) and whether this relation is influenced by the taper angle difference between male and female taper angles. Neck adapters made of titanium (Ti6Al4V) and $\mathrm{CoCr}$ (CoCr29Mo) were assembled with a titanium stem using varying assembly forces and mechanically loaded. A contactless eddy current measurement system was used to record the relative motion between prosthesis stem and neck adapter. Higher relative motion was observed for $\mathrm{Ti}$ neck adapters compared to the CoCr ones $(p<0.001)$. Higher assembly forces caused increased seating distances $(p<0.00 \mathrm{I})$ and led to significantly reduced relative motion $(p=0.019)$. Independent of neck material type, prostheses with larger taper angle difference between male and female taper angles exhibited decreased relative motion $(p<0.00 \mathrm{I})$. Surgeons should carefully use assembly forces above $4 \mathrm{kN}$ to decrease the amount of relative motion within the taper interface. Maximum assembly forces, however, should be limited to prevent periprosthetic fractures. Manufacturers should optimize taper angle differences to increase the resistance against relative motion.
\end{abstract}

\section{Keywords}

Modular prosthesis, relative motion, assembly force, stem-neck interface, taper angle difference

Date received: 2 August 2015; accepted: 15 April 2016

\section{Introduction}

Bi-modular prostheses showed increased popularity during the last 20 years due to their capability to adapt the prosthesis geometry to the individual anatomical situation, in order to achieve good reproduction of the anatomical hip joint centre. The intraoperative selection of a suitable neck adapter is convenient for the surgeon as it allows variation of neck length, femoral offset, caput collum diaphysis (CCD) angle and femoral head version. ${ }^{1}$ While some studies reported a reduced dislocation rate, ${ }^{2-4}$ only few data are currently available to confirm the acclaimed benefits of bi-modular systems. ${ }^{5}$ However, since overall bi-modular prostheses exhibit a clearly higher revision risk, their use is decreasing. The Australian Joint Registry 2013 reported 8971 primary total conventional hip procedures with bi-modular neck adapters, resulting in $3.6 \%$ of primary total hip arthroplasty (THA) in 2013 in comparison to $6.8 \%$ of primary THA in $2010 .^{6}$ The main reason for this fast decline is the high number of reported post-operative problems with modular neck adapters. ${ }^{7,8}$ Cumulative revision rates for bi-modular hip prostheses exceed those for modular systems with fixed neck adapters

\footnotetext{
'Institute of Biomechanics, Hamburg University of Technology (TUHH), Hamburg, Germany

${ }^{2}$ Centre for Orthopaedic Biomechanics, Department of Mechanical Engineering, University of Bath, Bath, UK
}

\section{Corresponding author:}

Henning Haschke, Institute of Biomechanics, Hamburg University of Technology (TUHH), Denickestraße 15, 21073 Hamburg, Germany. Email: haschke@tuhh.de 
$(10.8 \%$ vs $6.4 \%) \quad 10$ years postoperatively. ${ }^{6}$ Those increased revision rates for bi-modular prostheses are independent of the bearing surface material, except for metal on metal, which has high rates for both types. ${ }^{6}$ Early revision rates for some bi-modular hip prosthesis designs exceed others by a factor 4 (range: between $2.7 \%$ and $11.9 \%$ after 3 years implantation time $)^{6}$ and were the reason for voluntary recalls of some designs by several manufacturers during the last decade. ${ }^{5}$

Ten years postoperatively, the main incidences of revision are still aseptic loosening (3.6\% bi-modular vs $1.9 \%$ for fixed neck), prosthesis dislocation (1.7\% vs $1.0 \%)$, bone fracture $(1.3 \%$ vs $0.8 \%)$ and infection $(1.2 \%$ vs $0.8 \%) .{ }^{6}$ Neck adapter fractures have also been reported. ${ }^{1,9}$ They occur most likely after a relatively short time postoperatively due to fretting corrosion (mean: 24 month, range: $8-48$ months). ${ }^{1}$ However, it is still unclear, why a specific design fails in some patients but not in others.

Corrosion of tapers is influenced by two factors: relative motion above a critical level that leads to a disruption of the constantly rebuilding passivation layer ${ }^{8,10}$ and the presence of a fluid in the body. ${ }^{11}$ Due to the natural fluid environment, all implanted metallic materials are exposed to mechanically assisted corrosion, which can lead to a progressive surface damage (fretting). ${ }^{12,13}$ The crevice-like environment inherent to taper junctions adds to the severity of corrosion., ${ }^{7,14}$ Corrosion products were found in periprosthetic tissue, ${ }^{15-18}$ especially for modular systems. ${ }^{15,19}$ Metallic debris can lead to severe adverse tissue reactions and degradation of bone in the adjacent region, ${ }^{13,16,20}$ leading to revision indications such as aseptic loosening, ${ }^{21}$ bone fracture ${ }^{22}$ or metal-related pathologies. ${ }^{22,23}$ Clinically, a release of metallic wear from modular interfaces into the adjacent tissue has recently become a serious issue. $^{24-26}$

Previous studies have indicated that relative motion during loading above a critical level between the male and female taper might be a reason for an increased risk of fretting-induced fatigue. ${ }^{10,27}$ Situations of daily living are associated with high forces and moments as well as high repetitions. ${ }^{28,29}$ Due to the large lever arm and loading in bending of the neck adapters, the taper junction of bi-modular prostheses is located in an area of high moments, which further increases the risk of relative motion. ${ }^{30,31}$ The amount of relative motion is influenced by several factors. These include technical aspects, such as the influence of material coupling ${ }^{1,30}$ and the magnitude of manufacturing tolerances, especially with respect to the taper angles. ${ }^{10,32}$ Intraoperative aspects also play a decisive role: contamination of the taper junctions was shown to cause increased relative motion. ${ }^{30}$ Other aspects such as the influence of assembly force on seating and the amount of relative motion may affect the extent of fretting corrosion. ${ }^{33}$ The purpose of this study was to investigate the influence of material coupling, taper angle difference and assembly force on relative motion and seating at the stem-neck interface of one specific design of a bi-modular hip prosthesis.

\section{Materials and methods}

A total of 24 bi-modular hip prostheses (Metha ${ }^{\circledR}$, size 4, Aesculap AG, Tuttlingen, Germany) were used in this study. They consist of a stem made of a Ti6A14V alloy (Ti; ASTM F136; n = 24) and a neck adapter made of either the same $\mathrm{Ti}(\mathrm{n}=12)$ or CoCr29Mo alloy $(\mathrm{CoCr}$; $\mathrm{n}=12$; ASTM F1537; Figure 1). All adapters had a common CCD angle of $135^{\circ}$ and neutral version. The geometry of the tapers of the modular neck adapter (male) and the stem (female) consists of two hemitapers connected by flats. Prior to mechanical testing, the geometry was determined using a coordinate measuring machine (Mitutoyo BHN 305; Mitutoyo Deutschland, Neuss, Germany), and the taper angles were calculated. Taper angle difference $(\gamma=\alpha-\beta$; Figure 1) was defined as the difference between the male neck adapter's taper angle $(\alpha)$ and the female stem's taper angle $(\beta) .{ }^{10}$ For mechanical testing, the distal part of the stems was embedded in polymethylmethacrylat (PMMA; Technovit 4004; Heraeus Kulzer GmbH, Wehrheim Ts., Germany) according to ISO 7206-4 (10 $0^{\circ}$ adduction and $9^{\circ}$ flexion; Figure 2$)$.

Stem, neck adapter and ball head (CoCr29Mo, Ø $32 \mathrm{~mm}$, size L) were manually put together and then assembled by a single impaction applied with a drop weight $(7.9 \mathrm{~kg})$ in the direction of the taper axis (Figure 3). Assembly forces of $F_{1}=2 \mathrm{kN}, F_{2}=4 \mathrm{kN}$ and $\mathrm{F}_{3}=6 \mathrm{kN}$ corresponding to clinically observed forces were used. ${ }^{34}$ The height of the drop weight was determined based on calibration measurements using a force sensor (PCB 208C05; PCB Piezotronics, Depew, NY) attached to an analog-to-digital (A/D) converter (f $=100 \mathrm{kHz}, \quad$ RogaDAQ16; ROGA Instruments, Waldalgesheim, Germany).

This study consists of two parts. First, the seating behaviour during assembly (primary seating) and the position of the interlock were investigated. Second, the

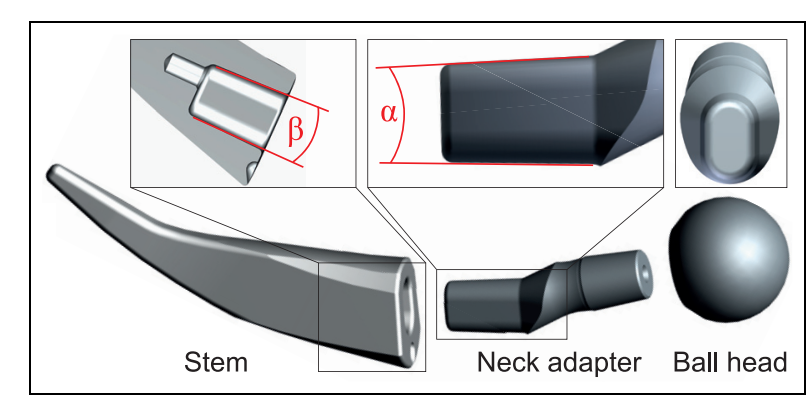

Figure I. Bi-modular hip prosthesis used in the experiments consisting of a stem, neck adapter and ball head with a female stem taper angle $(\beta)$ and a distal male taper angle $(\alpha)$. The top right insert shows a top view of the male neck adapter taper consisting of two hemi-tapers and two flats. 


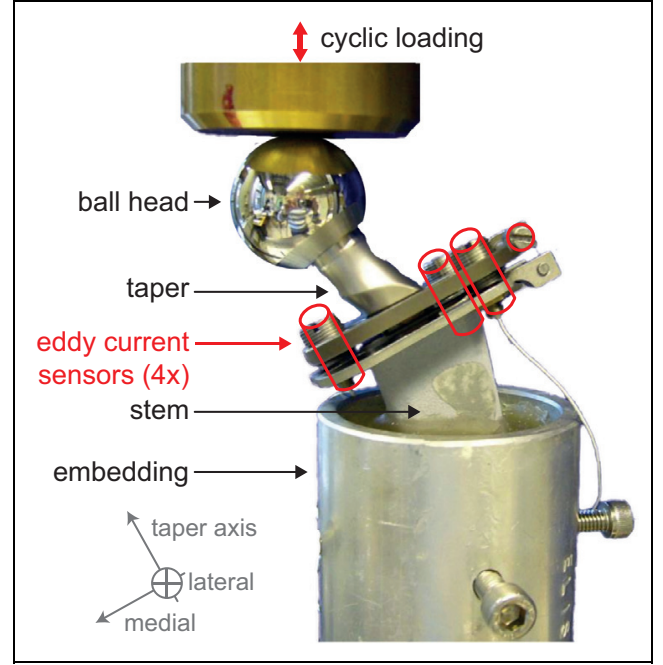

Figure 2. Test setup during mechanical load application. Relative motion between the neck adapter and the stem was recorded using eddy current sensors. Sensors were mounted to the distal holder and measured relative displacement to the proximal reflectors (screws) without direct contact.

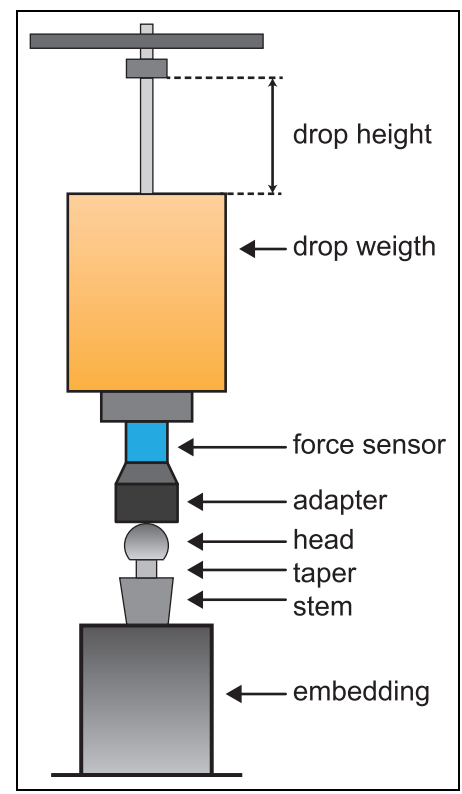

Figure 3. Drop weight used to assemble components of modular hip prosthesis. The attached force sensor was used to control the applied assembly forces. The appropriate drop height for the desired assembly forces of 2, 4 and $6 \mathrm{kN}$ was identified during pilot measurements, respectively.

resulting relative motion and seating (secondary seating) after cyclic mechanical loading were analysed.

\section{Primary seating}

A total of 18 neck adapters (Ti: 9; CoCr: 9; each assembly force $n=3$ ) were used to determine the primary seating behaviour and the approximation of the

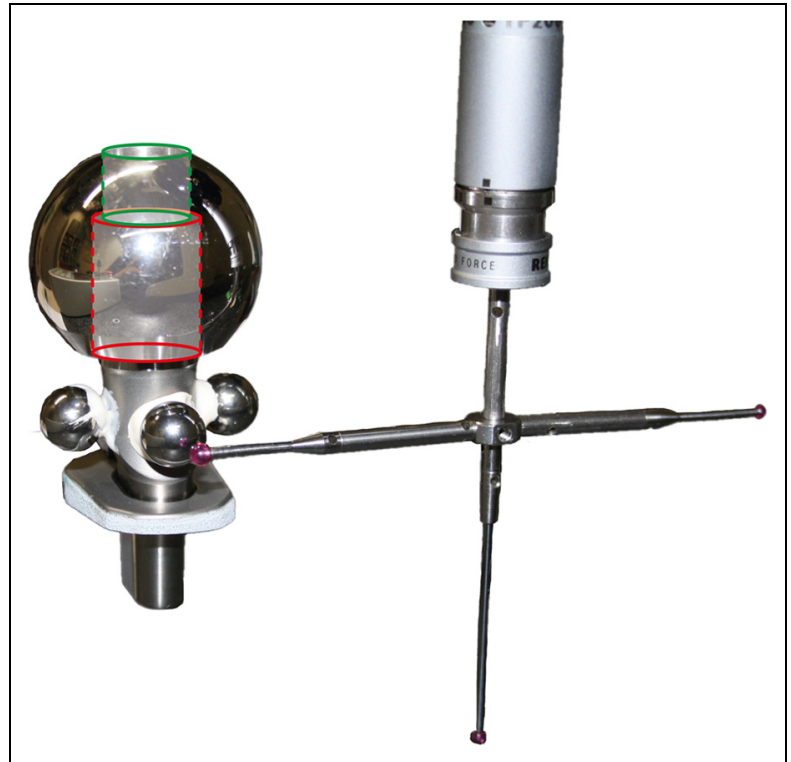

Figure 4. Measurement setup for the determination of seating distances at the taper junction using reference markers. A coordinate measurement machine obtained the positions of the proximal plane of the neck adapter, ball head centre, reference markers and proximal stem plane.

interlock's position at the taper interface. The amount of primary seating was assessed using a coordinate measuring machine (Mitutoyo BHN 305; Mitutoyo Deutschland). Three spherical markers (Ø $9 \mathrm{~mm}$, 100Cr6) were glued (X60; HBM GmbH, Darmstadt, Germany) on the surface of the taper in lateral, anterior and posterior directions, respectively (Figure 4). The markers were used to determine the position of the neck adapter based on their distance to the distal plane of the neck adapter $\left(\mathrm{L}_{1}\right)$, which was determined prior to assembly. Primary seating was determined as the change in the distance between the three spherical markers and the proximal plane of the stem $\left(\mathrm{L}_{2}\right)$ between the manually assembly and after the assembly forces were applied $\left(\Delta \mathrm{L}_{2}=\mathrm{L}_{2}\right.$, before $\left.-\mathrm{L}_{2 \text {,after }}\right)$. The depth of insertion of the neck adapter into the female stem taper was determined as the difference between proximal plane of the stem and distal plane of the neck adapter $\left(\mathrm{L}_{3}=\mathrm{L}_{1}-\mathrm{L}_{2}\right)$. The seating distance of the head $\left(\mathrm{L}_{4}\right)$ was determined through a central hole in the ball head (Ø $8 \mathrm{~mm} ; \Delta \mathrm{L}_{4}=\mathrm{L}_{4 \text {,before }}-\mathrm{L}_{4 \text {,after }}$; Figure 5). A finite element analysis showed no influence of the additional hole on the radial stiffness of the head, which could have altered the seating characteristics.

Statistical analysis was performed using parametrical statistics (regressions, one-way or two-way analysis of variance (ANOVA), analysis of covariance (ANCOVA); SPSS Statistics 21; IBM Corporation, Armonk, NY). In case of non-normal distributed data or inhomogeneity of variance, non-parametric tests (Kruskal-Wallis test) were used. A Z-transformation was used to determine the influence of taper angle differences on the relative motion. The type I error probability was set to $\alpha=0.05$. 


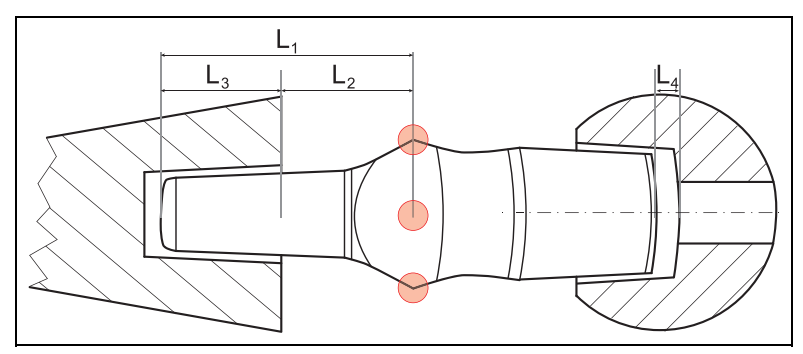

Figure 5. Definition of the seating distances at the two taper junctions and position of the reference markers (red). Primary seating of the neck adapter into the stem was defined as the change in $\Delta \mathrm{L} 2$, depth of insertion calculated as $\mathrm{L} 3=\mathrm{LI}-\mathrm{L} 2$. The head's seating distance is described by $\Delta \mathrm{L} 4$.

\section{Secondary seating and relative motion analysis}

Six prostheses consisting of Ti stems and either a Ti or a CoCr neck adapter ( $n=3$ each) were used. Each specimen was assembled consecutively with different assembly forces $(2,2,4,2,6$ and $2 \mathrm{kN})$. After each assembly, the specimens were mechanically loaded and afterwards disassembled before being assembled with the next assembly force yielding a total of 6 tests for each prosthesis and 36 tests in total. In order to identify a potential influence of the consecutive test protocol on the interface micromotion due to taper surface damage, the $2-\mathrm{kN}$ assembly load level was repeated after each assembly force group. Ball heads and neck adapters were also disassembled after each test. Mechanical testing was performed using a servo hydraulic testing machine (Mini Bionix II; MTS, Eden Prairie, MN). Force-controlled axial sinusoidal load between 0.23 and $4.3 \mathrm{kN}$ (corresponding to the magnitude of the vertical component of the hip reaction force for stair climbing as determined in vivo) ${ }^{35}$ was applied at $1 \mathrm{~Hz}$ for a total of 2000 cycles (Figure 2).

The relative motion at the stem-neck interface during mechanical testing was recorded using four contactless eddy current sensors (U05(78), Micro-Epsilon, Ortenburg, Germany; measurement range: $500 \mu \mathrm{m}$, resolution: $0.05 \mu \mathrm{m}$ ). The sensor holder was rigidly fixed to the stem and the holder for the counterparts (St 37) on the neck adapter (Figure 2). The relative motion between stem and neck adapter at the most lateral point of the taper junction was determined using coordinate transformations of the difference between maximum and minimum displacement of the four sensor signals for each loading cycle. This point represents the area where several neck adapters failed clinically. ${ }^{1}$ Further details on the contactless measurement system are reported elsewhere. ${ }^{36}$ The relative motion includes both the interface micromotion and the elastic deformation of the prosthesis between sensor holder and reflector.

Two parameters were used to describe the secondary seating behaviour of the neck adapter: amount of seating (relative displacement of the neck along the neck centre axis) and seating duration (reaching the fivefold of the time constant $(5 \times \tau)$ of an exponential

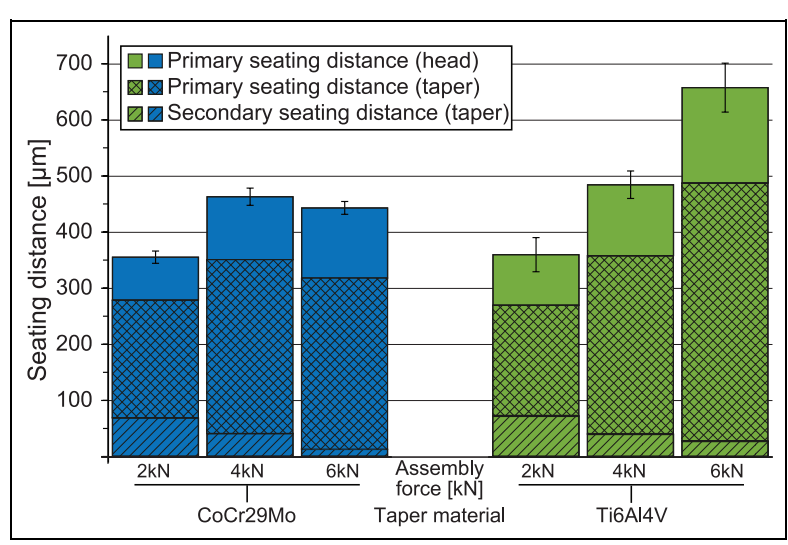

Figure 6. Total (primary and secondary) seating distance for the different neck materials and assembly forces. Seating increased with higher assembly forces for neck adapters made of $\mathrm{Ti}$, while $\mathrm{CoCr}$ neck adapters showed no further seating distance for an assembly force of $6 \mathrm{kN}$.

function ${ }^{10}$ ). Total seating was defined as the sum of primary and secondary seating.

\section{Surface investigation using microscopy}

After mechanical testing, the surfaces of the conical taper junctions were assessed on the macro- and the microscale. Five transversal sections at $3 \mathrm{~mm}$ distances starting at the proximal plane of the stem (mean thickness: $3 \mathrm{~mm}$ ) of four prostheses (CoCr with 4 and $6 \mathrm{kN}$ assembly forces, Ti with 2 and $6 \mathrm{kN}$ assembly forces) were prepared with a diamond saw (EXAKT $3031 \mathrm{CP}$ $\mathrm{N}$; EXAKT Advanced Technologies $\mathrm{GmbH}$, Norderstedt, Germany). The surfaces of the transversal sections were polished with a water-cooled polishing table (Knuth-Rotor, Struers A/S, Ballerup, Denmark) using decreasing grain size $(4000-180 \mu \mathrm{m})$. The cross sections were analysed using an infinite focus variation (IFV) microscopy (Infinite Focus; Alicona Imaging GmbH, Grambach, Austria) and scanning electron microscopy (SEM; Leo 1530; Zeiss, Oberkochen, Germany). Taper junction gap size between neck adapter and stem was determined.

\section{Results}

\section{Primary seating}

The force impact exhibited by the dropped weight produced a reproducible assembly force with standard deviations in the three assembly force groups (2000, 4000 and $6000 \mathrm{~N}$ ) of $3.2 \%, 1.1$ and $1.5 \%$, respectively. The primary seating distance of the neck adapter increased with assembly forces ( $p<0.001$, two-way ANOVA; Figure 6) from 197.3 $\pm 60.2 \mu \mathrm{m}(\mathrm{Ti}, 2 \mathrm{kN})$ to $460.1 \pm 84.5 \mu \mathrm{m}(\mathrm{Ti}, 6 \mathrm{kN})$. The effect was stronger for Ti compared to CoCr neck adapters (Figure 6).

Seating of the ball head on the neck adapter also increased with assembly force $(\mathrm{p}<0.001$, two-way ANOVA; Figure 6) and ranged from $76.3 \pm 5.0 \mu \mathrm{m}$ 
Table I. Amount of total seating and magnitude of relative motion for the different neck materials and assembly forces.

\begin{tabular}{lllll}
\hline Assembly force $(\mathrm{kN})$ & \multicolumn{2}{l}{ Total seating of taper $(\mu \mathrm{m})$} & & \multicolumn{2}{l}{ Relative motion $(\mu \mathrm{m})$} \\
\cline { 2 - 5 } \cline { 5 - 6 } & $\mathrm{Ti}$ & $\mathrm{CoCr}$ & $\mathrm{Ti}$ & $\mathrm{COCr}$ \\
\hline 2 & 269.7 & 278.8 & 13.41 & 7.61 \\
6 & 358.0 & 350.9 & 12.13 & 7.41 \\
6 & 487.6 & 318.0 & 11.34 & 6.69 \\
\hline
\end{tabular}

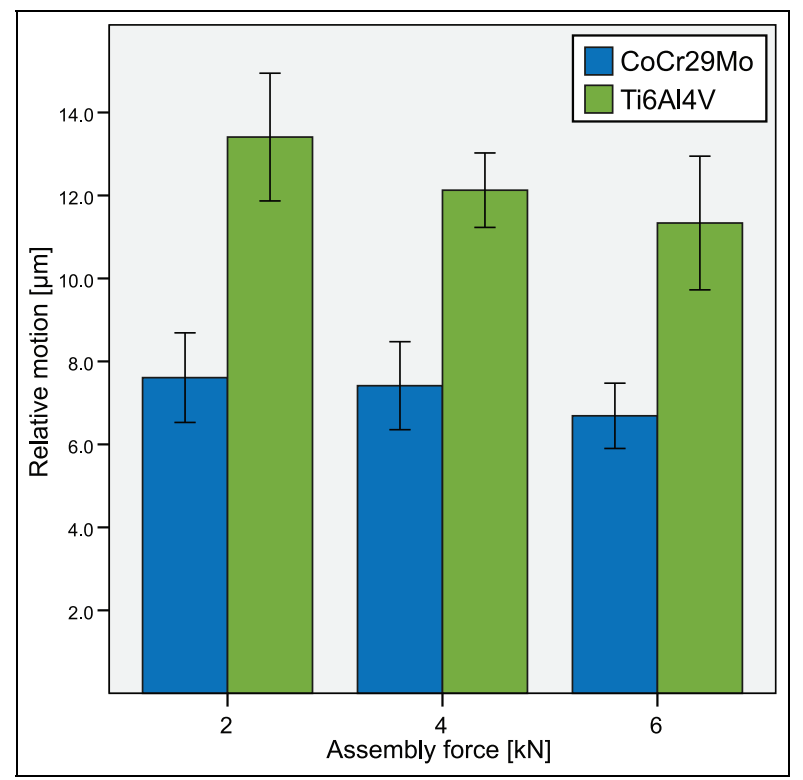

Figure 7. Ti neck adapters showed significant higher relative motion between neck adapter and stem than the CoCr ones. Higher assembly forces exhibited smaller relative motion for both material couplings.

$(\mathrm{CoCr}, 2 \mathrm{kN})$ to $169.6 \pm 37.0 \mu \mathrm{m}(\mathrm{Ti}, 6 \mathrm{kN})$. Ti neck adapters showed significantly larger seating distances at the neck-head interface ( $\mathrm{p}=0.021$; two-way ANOVA). Primarily seating distances at the stem-neck taper were about three times higher than at the neck adapter-ball head taper (Figure 6).

Secondary seating and relative motion analysis. Relative motion between stem and neck adapter did not change due to the consecutive measurements with a similar assembly force of $2 \mathrm{kN}$ ( $\mathrm{p}=0.496$, two-way ANOVA). Ti neck adapters showed significantly higher relative motion compared to $\mathrm{CoCr}$ ones ( $\mathrm{p}<0.001$, two-way ANOVA; Figure 7; Table 1). Higher assembly forces significantly reduced the relative motion $(\mathrm{p}=0.019$, ANCOVA; Figure 7).

The taper angle differences were positive for all cases and ranged from $0.076^{\circ}$ to $0.130^{\circ}$. Relative motion (all materials) at the stem-neck interface decreased with increasing taper angle difference $\left(R^{2}=0.61\right.$, $\mathrm{p}<0.001$, linear regression; Figure 8). The effect was nearly identical for both neck adapter materials (Ti: $\mathrm{R}^{2}=0.763, \mathrm{p}<0.001 ; \mathrm{CoCr}: \mathrm{R}^{2}=0.741, \mathrm{p}<0.001 ;$ linear regressions).

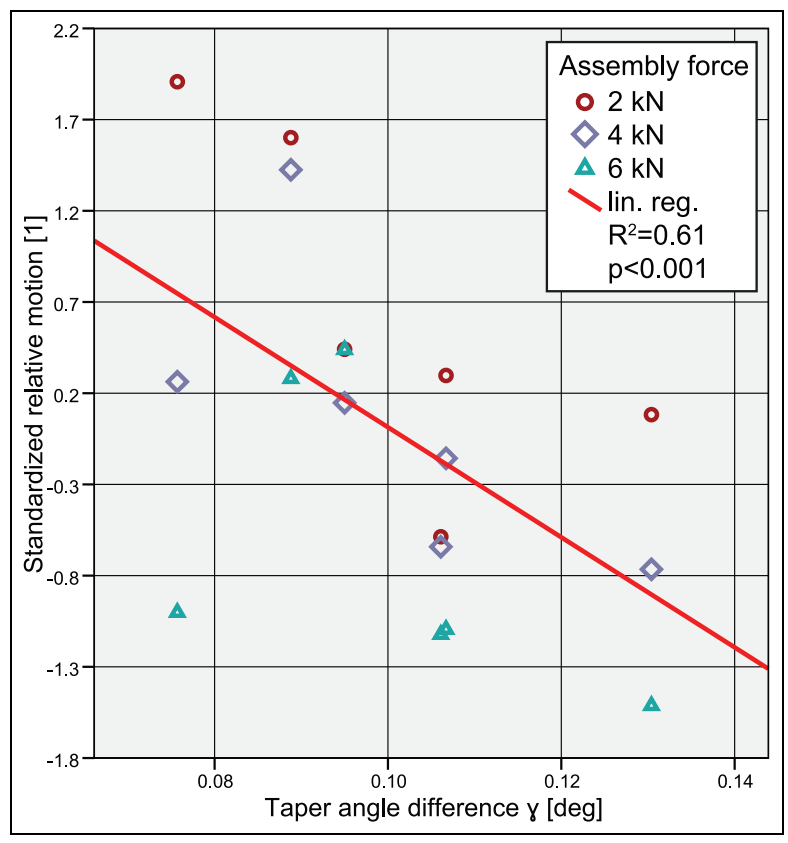

Figure 8. Amount of relative motion decreased with increasing taper angle difference independent of neck adapter material.

Consecutive experiments did not alter the secondary seating distance: all experiments performed with the same assembly force yielded similar secondary seating distances ( $p=0.889$, one-way ANOVA; Table 2) and seating durations $(p=0.109$; Kruskal-Wallis test) due to mechanical cyclic loading. The secondary seating of the neck adapter into the stem was finished after $26.8 \pm 5.5$ loading cycles and was identical for neck adapters made of $\mathrm{Ti}$ and $\mathrm{CoCr}(\mathrm{p}=0.816$, two-way ANOVA). Increasing assembly forces lead to significantly shorter seating durations $\left(\mathrm{t}_{2 \mathrm{kN}}=28.8 \pm\right.$ 4.9 cycles, $\mathrm{t}_{6 \mathrm{kN}}=21.7 \pm 4.5$ cycles, $\mathrm{p}=0.006$, two-way ANOVA; Figure 9).

Secondary seating distances for the neck adapter during cyclic loading varied between $12.8 \pm 2.9 \mu \mathrm{m}$ and $72.4 \pm 9.0 \mu \mathrm{m}$ and decreased with higher assembly forces ( $\mathrm{p}<0.001$, two-way ANOVA; Figures 6 and 9). The choice of material coupling had no influence on the secondary seating distance of the neck adapter except for a trend towards larger seating distances for $\mathrm{Ti}$ at high assembly forces $(\mathrm{F}=6 \mathrm{kN}, \mathrm{p}=0.139$, two-way ANOVA; Table 2). The total seating distance decreased linearly with increasing taper angle difference for neck adapters made of $\mathrm{Ti}\left(\mathrm{R}^{2}=0.99 ; \mathrm{p}=0.008\right.$; linear 
Table 2. Secondary seating distances and durations for the different neck materials and assembly forces.

\begin{tabular}{|c|c|c|c|c|}
\hline \multirow[t]{2}{*}{ Assembly force $(\mathrm{kN})$} & \multicolumn{2}{|c|}{ Seating duration of taper (s) } & \multicolumn{2}{|c|}{ Secondary seating of taper $(\mu \mathrm{m})$} \\
\hline & $\mathrm{Ti}$ & $\mathrm{CoCr}$ & $\mathrm{Ti}$ & $\mathrm{CoCr}$ \\
\hline 2 (first test) & 24.0 & 35.0 & 72.5 & 73.8 \\
\hline 2 (second test) & 22.7 & 27.3 & 64.2 & 74.7 \\
\hline 2 (third test) & 32.3 & 27.7 & 73.1 & 64.8 \\
\hline 2 (fourth test) & 32.0 & 27.7 & 79.6 & 62.0 \\
\hline 2 (mean) & 28.1 & 29.4 & 72.4 & 68.8 \\
\hline 4 & 22.5 & 24.7 & 40.1 & 40.9 \\
\hline 6 & 22.7 & 20.7 & 27.5 & 12.8 \\
\hline
\end{tabular}

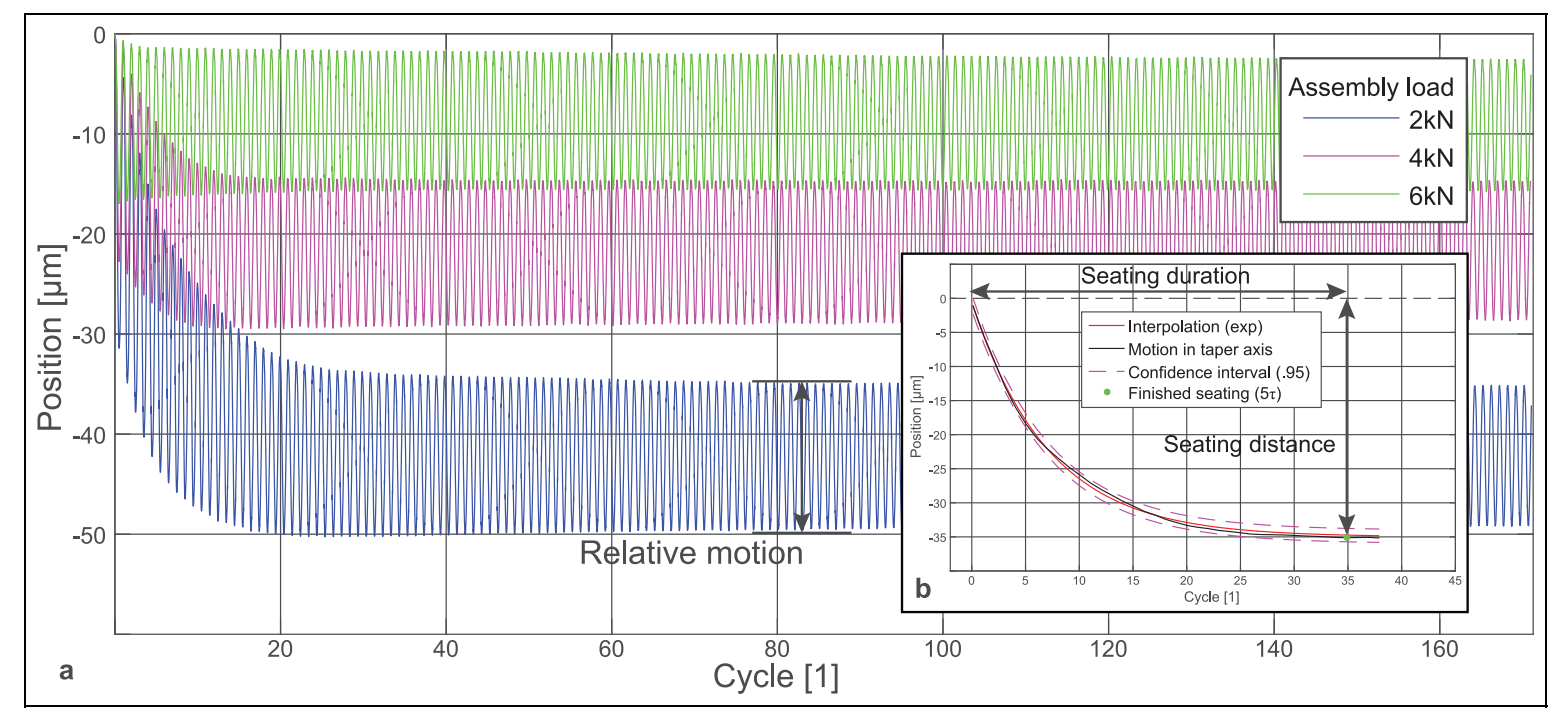

Figure 9. (a) Higher assembly forces led to significantly reduced secondary seating distances and seating durations (CoCr). (b) The seating behaviour was characterized with an interpolation (exponential function). Seating distance and duration were measured at the fivefold time constant $(5 \tau)$.

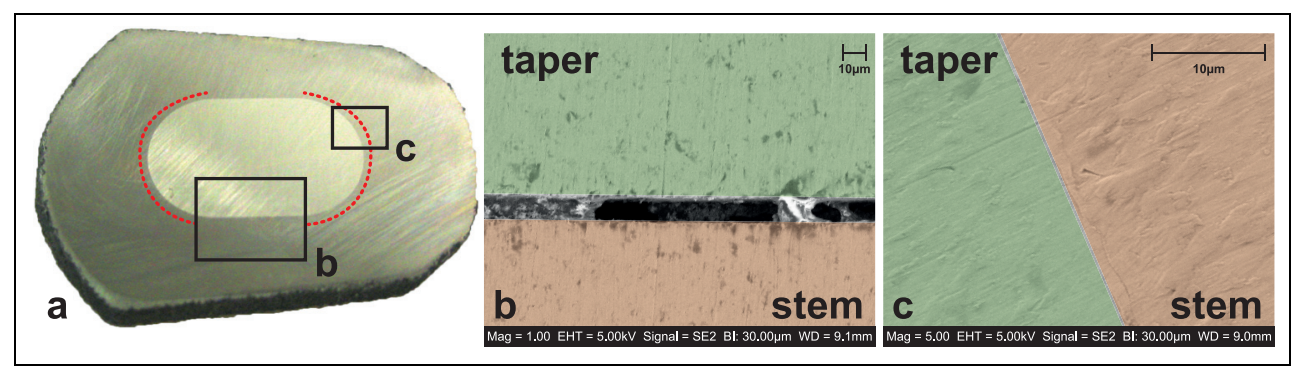

Figure 10. (a) Transversal section through stem (Ti) and neck adapter ( $\mathrm{CoCr}$ ) after assembly with $6 \mathrm{kN}$, (b) coloured SEM image of the anterior section of the taper interface and (c) coloured SEM image of the medio-posterior edge. The taper interlock is located in the spherical sections in the medial and lateral directions (dashed red line), while a clear gap with contaminations is visible at the anterior and posterior sections.

regression). The total seating distance also increased with higher assembly forces for neck adapters made of $\mathrm{Ti}$, while CoCr neck adapters levelled out at an assembly force of $4 \mathrm{kN}$ (Figure 6; Table 1).

Surface investigation using microscopy. No visual surface damage was found at the neck adapter-stem taper interfaces. SEM images showed traces of $\mathrm{TiO}_{2}$ (up to
$5 \mu \mathrm{m}$ thick) at the interface gap of the cut prostheses (Figure 10(a)). In posterior and anterior directions, male and female taper were not in direct contact (gap width $20-30 \mu \mathrm{m}$; Figure 10(b)), while no gap was visible in the medial and lateral directions (Figure 10(c)). The gap size increased from 2 (plane 1 at the proximal end of the prosthesis) up to $170 \mu \mathrm{m}$ (plane $51.5 \mathrm{~cm}$ distal from the proximal end of the prosthesis) in the 


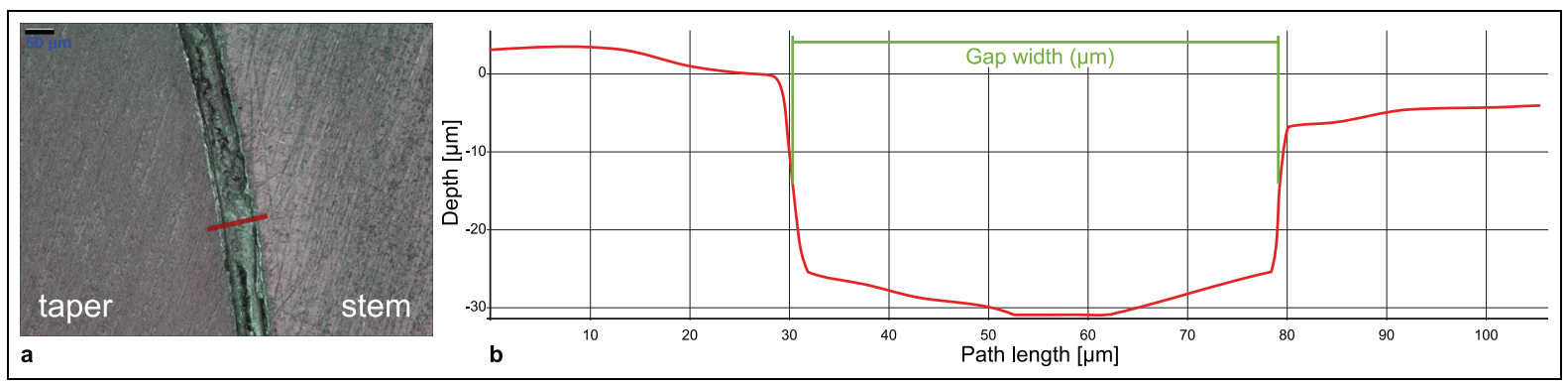

Figure I I. (a) Infinite focus variation image of the gap between neck and stem taper on the anterior side of section 4 and (b) measurement of the gap width $(50 \mu \mathrm{m})$. The finite depth is due to the residue of the polishing process.

anterior-posterior direction (Figure 11). The position of the interlock between neck adapter and stem was found to be located $7 \mathrm{~mm}$ from the distal plane of the neck adapter.

\section{Discussion}

Fretting-induced surface damage is more often expressed in titanium alloys compared to $\mathrm{CoCr}^{8,11,31,37}$ Accordingly, clinical failures of the prosthesis design $\left(\right.$ Metha $\left.^{\circledR}\right)$ occurred only in neck adapters made of $\mathrm{Ti}^{1,38}$ which showed the higher relative motion compared to CoCr ones. ${ }^{30}$ The choice of material for the neck adapter had the biggest influence on relative motion of all parameters investigated. This is to a considerable extend caused by the large differences in Young's modulus between the materials leading to a higher elastic deformation for Ti neck adapters during loading (Ti: $115 \mathrm{GPa}, \mathrm{CoCr}$ : $225 \mathrm{GPa}$ ). Elastic deformation for the investigated prosthesis design accounts for $85.9 \%(\mathrm{Ti})$ and $97.7 \%(\mathrm{CoCr})$ of the measured relative motion between neck adapter and stem. ${ }^{39}$ Approximately $60 \%$ of the difference in relative motion between $\mathrm{Ti}$ and $\mathrm{CoCr}$ neck adapters can be explained by the different Young's moduli of the materials. Loading direction was not changed during testing to reflect only one discrete loading condition that occurs clinically $\left(10^{\circ}\right.$ adduction, $9^{\circ}$ flexion) and is defined by the ISO 7206-04 standard. Therefore, the amount of micromotion within the interface might further increase due to other activities and high joint friction moments, which have been reported from in vivo measurements, especially in poorly lubricated situations. ${ }^{40}$

Low intraoperative assembly forces $(\mathrm{F} \leqslant 2 \mathrm{kN})$ were not sufficient to ensure a friction-locked connection between the neck adapter and the stem for load transmission as can be seen in the high secondary seating distances for low assembly forces (for Ti neck adapters, $24.7 \%$ of total seating at $\mathrm{F}=2 \mathrm{kN}$ and $4.0 \%$ at $\mathrm{F}=6 \mathrm{kN}$; Figure 6). Experiments with the same prosthesis design quasi-statically assembled with a force of $500 \mathrm{~N}$ even showed values of $82 \%-92 \%{ }^{36}$ Secondary seating distances up to $86 \mu \mathrm{m}$ determined in this study might not be clinically relevant in terms of prosthesis dislocation or malpositioning but rather an indicator for large interface motion after implantation. ${ }^{33}$ The seating behaviour of the neck adapter into the stem taper was strongly influenced by the taper angle difference and material. Neck adapters made of $\mathrm{CoCr}$ reached a final seating distance at $4 \mathrm{kN}$, while no such seating maximum was found for Ti.

The initial seating provided by the assembly force might have an effect on the long-term outcome of the prosthesis as the extent of clinical fretting is influenced by various factors. ${ }^{30,32,33,41,42}$ Relative motion is an indicator for the strength of the taper interlock. ${ }^{43}$ Reduced relative motion can contribute to a reduction of wear and corrosion potential. ${ }^{26}$ Although forces during cyclic loading $\left(F_{\max }=4300 N\right)$ were higher than two of the assembly force groups, the difference in seating depth between the assembly force groups was still present after 2000 loading cycles, indicating that cyclic loading does not provide similar seating as higher assembly forces within the amount of loading cycles used in this experiment. Further seating after the secondary seating was within the measurement error for all assembly loads (Figure 9). A high variation of applied assembly forces was observed between different surgeons: Nassutt et al. ${ }^{34}$ reported an assembly force range of $273 \pm 24-7848 \pm 1331 \mathrm{~N}$, and Heiney et al. ${ }^{44}$ found a mean assembly force of $4346 \pm 939 \mathrm{~N}$ for resident orthopaedic surgeons. The influence of assembly procedure on the strength of the taper connection has been shown previously, and assembly forces of 4-6 kN have been suggested. ${ }^{45,46}$ This is well below the force needed to fracture the femur (internal data). Training of surgeons or additional tools such as an automatic impactor might further support a controlled intraoperative assembly of the implant components.

Larger taper angle differences within the range investigated were shown to produce lower relative motion at the taper interface, probably due to the increased contact pressure as a consequence to the lower contact area. Other studies report controversial results with respect to taper angle differences: No correlation between the taper angle differences and taper fretting between stem and head taper ${ }^{32}$ and significant influence on the fretting rate ${ }^{47}$ are reported. This might 
indicate that the specific design, such as a circular taper and a non-circular taper geometry, might also influence the situation. ${ }^{5}$

Visual inspection of the neck adapters indicated a diagonal interlock from posterolateral to anteromedial or anterolateral to posteromedial in the taper interface. Due to the positive taper angle differences, the initial contact between the two prosthesis components was always proximal. The position of the interlock was determined approximately $7 \mathrm{~mm}$ from the distal plane. The location of crack formation and implant failure during high cycle loading tests was found proximal to this location in an area where rather high micromotion can be assumed. ${ }^{1}$ The location of the interlock is a function of different design- and assembly-related parameters. It might be possible that shifting the position of the interlock closer to the proximal plane might reduce micromotion and seal the taper interface distally to the interlock; this should be addressed in future studies. The limited number of cut prostheses in this study does not allow a final conclusion.

\section{Conclusion}

Several factors have an impact on relative motion at the taper interface. ${ }^{30,48,49}$ This study demonstrates how design and assembly parameters influence the amount of relative motion in one bi-modular hip prosthesis design. Although the use of bi-modular hip prostheses has declined due to increased issues with corrosion, the underlying idea of modular systems is still of interest, and a better understanding of taper junctions is also required since similar problems have also been reported for single-modular prostheses. ${ }^{50-53}$ Taper angle differences of modular junctions differ quite greatly between manufacturers. General design guidelines are not available, leading to a variety of taper geometries. ${ }^{5}$ This study has shown that the taper angle difference might be an effective tool to reduce relative motion at the taper and resulting corrosion issues. Surgical instructions including the required assembly forces and assembly conditions are required in order to reduce the high variety of clinical outcome within a specific prosthesis design as each surgeon implements other techniques. In order to improve patient outcome, surgeons should avoid low assembly forces to decrease the amount of relative motion within the taper interface. An assembly force of at least $4 \mathrm{kN}$ is advisable in order to provide a suitable initial stability and avoid penetration of contaminations into the taper interface, which might negatively alter the position of the interlock. However, the maximum assembly force must be limited to prevent periprosthetic fractures.

\section{Acknowledgements}

The authors would like to thank the manufacturer B. Braun Aesculap AG for the cooperation and for providing the prosthesis components. The authors kindly acknowledge technical support of Prof. Thomas M. Grupp, PhD (R\&D, B. Braun Aesculap AG, Tuttlingen, Germany).

\section{Declaration of conflicting interests}

The author(s) declared the following potential conflicts of interest with respect to the research, authorship, and/ or publication of this article: All experimental studies were performed at the TUHH Hamburg University of Technology. The Institute of Biomechanics has received institutional support by B. Braun Aesculap AG.

\section{Funding}

The author(s) received no financial support for the research, authorship and/or publication of this article.

\section{References}

1. Grupp TM, Weik T, Bloemer W, et al. Modular titanium alloy neck adapter failures in hip replacement - failure mode analysis and influence of implant material. $B M C$ Musculoskelet Disord 2010; 11: 3.

2. Jolles B. Factors predisposing to dislocation after primary total hip arthroplasty. J Arthroplasty 2002; 17: 282-288.

3. Soong M, Rubash HE and Macaulay W. Dislocation after total hip arthroplasty. J Am Acad Orthop Surg 2004; 12: 314-321.

4. Hart AJ, Ilo K, Underwood R, et al. The relationship between the angle of version and rate of wear of retrieved metal-on-metal resurfacings: a prospective, CT-based study. J Bone Joint Surg Br 2011; 93: 315-320.

5. Krishnan H, Krishnan SP, Blunn G, et al. Modular neck femoral stems. Bone Joint J 2013; 95: 1011-1021.

6. Australian Orthopaedic Association National Joint Replacement Registry. 2013 annual report - Australian registry. Adelaide, SA: Australian Orthopaedic Association National Joint Replacement Registry, 2013.

7. Atwood SA, Patten EW, Bozic KJ, et al. Corrosioninduced fracture of a double-modular hip prosthesis: a case report. J Bone Joint Surg Am 2010; 92: 1522-1525.

8. Baxmann M, Jauch SY, Schilling C, et al. The influence of contact conditions and micromotions on the fretting behavior of modular titanium alloy taper connections. Med Eng Phys 2013; 35: 676-683.

9. Ellman MB and Levine BR. Fracture of the modular femoral neck component in total hip arthroplasty. $J$ Arthroplasty 2013; 28: 196.

10. Jauch SY, Huber G, Haschke H, et al. Design parameters and the material coupling are decisive for the micromotion magnitude at the stem-neck interface of bi-modular hip implants. Med Eng Phys 2014; 36: 300-307.

11. Gilbert JL, Buckley CA and Jacobs JJ. In vivo corrosion of modular hip prosthesis components in mixed and similar metal combinations. The effect of crevice, stress, motion, and alloy coupling. J Biomed Mater Res 1993; 27: $1533-1544$

12. Brown SA, Flemming CA, Kawalec JS, et al. Fretting corrosion accelerates crevice corrosion of modular hip tapers. J Appl Biomater 1995; 6: 19-26.

13. Gilbert JL, Sivan S, Liu Y, et al. Direct in vivo inflammatory cell-induced corrosion of CoCrMo alloy orthopedic 
implant surfaces. J Biomed Mater Res A 2015; 103: 211223.

14. Degat PR, Zhou ZR and Vincent L. Fretting cracking behaviour on pre-stressed aluminium alloy specimens. Tribol Int 1997; 30: 215-223.

15. Jacobs JJ, Urban RM, Gilbert JL, et al. Local and distant products from modularity. Clin Orthop Relat Res 1995; 319: 94-105.

16. Urban RM, Jacobs JJ, Gilbert JL, et al. Migration of corrosion products from modular hip prostheses. Particle microanalysis and histopathological findings. $J$ Bone Joint Surg Am 1994; 76: 1345-1359.

17. Langton DJ, Jameson SS, Joyce TJ, et al. Early failure of metal-on-metal bearings in hip resurfacing and largediameter total hip replacement: a consequence of excess wear. J Bone Joint Surg Br 2010; 92: 38-46.

18. Takamura K, Langton D, Gandhi J, et al. The main issue of large diameter MoM total hip arthroplasty: the taper junction. In: Proceedings of the annual meeting of the American academy of orthopaedic surgeons, San Francisco, CA, 7-11 February.

19. Garbuz DS, Tanzer M, Greidanus NV, et al The John Charnley Award: metal-on-metal hip resurfacing versus large-diameter head metal-on-metal total hip arthroplasty: a randomized clinical trial. Clin Orthop Relat Res 2010; 468: 318-325.

20. Viceconti M, Baleani M, Squarzoni S, et al. Fretting wear in a modular neck hip prosthesis. $J$ Biomed Mater Res 1997; 35: 207-216.

21. Huber M, Reinisch G, Trettenhahn G, et al. Presence of corrosion products and hypersensitivity-associated reactions in periprosthetic tissue after aseptic loosening of total hip replacements with metal bearing surfaces. Acta Biomater 2009; 5: 172-180.

22. Hallab NJ and Jacobs JJ. Biologic effects of implant debris. Bull NYU Hosp Jt Dis 2009; 67: 182-188.

23. Lombardi AV, Mallory TH, Vaughn BK, et al. Aseptic loosening in total hip arthroplasty secondary to osteolysis induced by wear debris from titanium-alloy modular femoral heads. J Bone Joint Surg Am 1989; 71: 13371342.

24. Meyer H, Mueller T, Goldau G, et al. Corrosion at the cone/taper interface leads to failure of large-diameter metal-on-metal total hip arthroplasties. Clinical Orthopaed Relat Res 2012; 470: 3101-3108.

25. Gill IPS, Webb J, Sloan K, et al. Corrosion at the neckstem junction as a cause of metal ion release and pseudotumour formation. J Bone Joint Surg Br 2012; 94: 895900.

26. Bishop N, Witt F, Pourzal R, et al. Wear patterns of taper connections in retrieved large diameter metal-onmetal bearings. J Orthop Res 2013; 31: 1116-1122.

27. Forschungskuratorium Maschinenbau e.V. Reibkorrosion - Vorhaben Nr. 6, 56.6000. Frankfurt am Main: Forschungsheft Maschinenbau-Verlag GmbH, 1976.

28. Bergmann G, Deuretzbacher G, Heller M, et al. Hip contact forces and gait patterns from routine activities. $J$ Biomech 2001; 34: 859-871.

29. Morlock M, Schneider E, Bluhm A, et al. Duration and frequency of everyday activities in total hip patients. $J$ Biomech 2001; 34: 873-881.

30. Jauch SY, Huber G, Hoenig E, et al. Influence of material coupling and assembly condition on the magnitude of micromotion at the stem-neck interface of a modular hip endoprosthesis. J Biomech 2011; 44: 1747-1751.

31. Duisabeau L, Combrade P and Forest B. Environmental effect on fretting of metallic materials for orthopaedic implants. Wear 2004; 256: 805-816.

32. Kocagöz SB, Underwood RJ, Sivan S, et al. Does taper angle clearance influence fretting and corrosion damage at the head-stem interface? A matched cohort retrieval study. Semin Arthroplasty 2014; 24: 246-254.

33. Mroczkowski ML, Hertzler JS, Humphrey SM, et al. Effect of impact assembly on the fretting corrosion of modular hip tapers. J Orthop Res 2006; 24: 271-279.

34. Nassutt R, Mollenhauer I, Klingbeil K, et al. Relevance of the insertion force for the taper lock reliability of a hip stem and a ceramic femoral head. Biomed Tech 2006; 51: 103-109.

35. Bergmann G, Graichen F, Rohlmann A, et al. Realistic loads for testing hip implants. Biomed Mater Eng 2010; 20: 65-75.

36. Jauch SY, Huber G, Sellenschloh K, et al. Micromotions at the taper interface between stem and neck adapter of a bimodular hip prosthesis during activities of daily living. J Orthop Res 2013; 31: 1165-1171.

37. Gilbert JL, Mali S, Urban RM, et al. In vivo oxideinduced stress corrosion cracking of Ti-6Al-4V in a neckstem modular taper: emergent behavior in a new mechanism of in vivo corrosion. J Biomed Mater Res B Appl Biomater 2011; 100: 584-594.

38. Wright G, Sporer S, Urban R, et al. Fracture of a modular femoral neck after total hip arthroplasty - a case report. J Bone Joint Surg Am 2010; 92: 1518-1521.

39. Jauch SY, Huber G, Haschke H, et al. Low CCD - angles cause higher micromotions at the neck taper junction of bi-modular hip stems. J Biomech 2012; 45: S315.

40. Damm P, Dymke J, Ackermann R, et al. Friction in total hip joint prosthesis measured in vivo during walking. PLoS One 2013; 8: e78373.

41. Goldberg JR, Gilbert JL, Jacobs JJ, et al. A multicenter retrieval study of the taper interfaces of modular hip prostheses. Clin Orthop Relat Res 2002; 149-161.

42. Pennock AT, Schmidt AH and Bourgeault CA. Morsetype tapers: factors that may influence taper strength during total hip arthroplasty. J Arthroplasty 2002; 17: 773778.

43. Gkagkalis G, Mettraux P, Omoumi P, et al. Adverse tissue reaction to corrosion at the neck-stem junction after modular primary total hip arthroplasty. Orthop Traumatol Surg Res 2015; 101: 123-126.

44. Heiney JP, Battula S, Vrabec GA, et al. Impact magnitudes applied by surgeons and their importance when applying the femoral head onto the Morse taper for total hip arthroplasty. Arch Orthop Trauma Surg 2009; 129: 793-796.

45. Rehmer A, Bishop NE and Morlock MM. Influence of assembly procedure and material combination on the strength of the taper connection at the head-neck junction of modular hip endoprostheses. Clin Biomech 2012; 27: 77-83.

46. Jauch SY, Coles LG, Ng LV, et al. Low torque levels can initiate a removal of the passivation layer and cause fretting in modular hip stems. Med Eng Phys 2014; 36: 1140-1146.

47. Donaldson FE, Coburn JC and Lohmann Siegel K. Total hip arthroplasty head-neck contact mechanics: a 
stochastic investigation of key parameters. $J$ Biomech 2014; 47: 1634-1641.

48. Shareef $\mathrm{N}$ and Levine D. Effect of manufacturing tolerances on the micromotion at the Morse taper interface in modular hip implants using the finite element technique. Biomaterials 1996; 17: 623-630.

49. Abdullah K. Study of factors affecting taper joint failures in modular hip implant using finite element modelling. In: Shkelzen C (ed.) Modeling simulation and optimization - focus on applications. Rijeka: InTech, 2010, pp.121-134.

50. Hussenbocus S, Kosuge D, Solomon LB, et al. Headneck taper corrosion in hip arthroplasty. Biomed Res Int 2015; 2015: 18-21.
51. McGrory BJ, MacKenzie J and Babikian G. A high prevalence of corrosion at the head-neck taper with contemporary Zimmer non-cemented femoral hip components. $J$ Arthroplasty 2015; 30: 1265-1268.

52. Nassif N, Nawabi DH, Stoner K, et al. Taper design affects failure of large-head metal-on-metal total hip replacements. Clin Orthop Relat Res 2014; 472: 564-571.

53. Higgs GB, Hanzlik JA, MacDonald DW, et al. Is increased modularity associated with increased fretting and corrosion damage in metal-on-metal total hip arthroplasty devices? A retrieval study. J Arthroplasty 2013; 28: 2-6. 